\title{
Management of Spontaneous Intracerebral Haemorrhage
}

\author{
Lt Col MN Swamy*
}

\begin{abstract}
Background: Management of spontaneous intracerebral haemorrhage (SICH) is still an enigma. The study was conducted to find out the most appropriate mode of treatment and other possible inclusion criteria's in addition to clot size.

Methods: Sixty consecutive patients of SICH excluding bleeds due to arteriovenous malformations/aneurysm were included in the study. Patients with moderate and large bleeds, progressive neurological deficit and glasgow coma scale (GCS) of more than five were included in the surgical group and rest treated conservatively.

Result: Location of the bleed, other co-morbid conditions and GCS at presentations were more important guidelines than size of the bleed. Mortality was more in surgically treated group where cerebellar bleed fared well after evacuation.

Conclusion: Surgery is preferred in superficially located bleeds and cerebellar bleeds. Intra cranial pressure monitoring will help in categorizing the mode of treatment better than mere clot size.
\end{abstract}

MJAFI 2007; 63 : 346-349

Key Words : Spontaneous intracerebral haemorrhage; Ischaemic penumbra; Ischaemic stroke.

\section{Introduction}

Spontaneous intracerebral haemorrhage $(\mathrm{SICH})$ is responsible for $10-15 \%$ of the acute stroke [1-3]. The common causes of SICH are hypertension, aneurysm, arteriovenous malformation (AVM), coagulopathies and vasculopathies [4-6]. Hypertensive bleed mainly occurs in putamen, near ruptured aneurismal site with or without subarachanoid haemorrhage/ventricular extension and at the site of AVM, while bleeding due to angiopathy is usually lobar $[7,8]$. The neurological status at the initial presentation and the interval between onset and therapeutic intervention contributes to the prognosis [9]. Computed tomography (CT) scan (level one evidence and grade A recommendation) for the initial assessement and digital substraction angiography (DSA) to establish or rule out aneurysm/arteriovenous malformations are the investigations of choice [10].

The lack of consensus for the treatment of SICH has led to great variation in surgical and medical management [11-13]. Guidelines based on scant data from few randomised and many nonrandomised trials are uncertain at best [10]. All the studies emphasise on early evacuation of clot in case surgery is chosen as the treatment option [14-16]. This observational study aimed at identifying appropriate intervention.

\section{Material and Methods}

Sixty consecutive patients with SICH excluding bleeds due to AVM/aneurysm over a period of one year at a tertiary care hospital, were included in the study. Glasgow coma scale (GCS) and the initial blood pressure were recorded at admission and after six hours. All the patients were evaluated with CT scan to assess the size, shape, location and volume of haematoma [17]. Based on the volume of the clot the bleed was grouped as small $(<20 \mathrm{cc})$, moderate $(21-40 \mathrm{cc})$ and large $(>40 \mathrm{cc}$ ). Patients were also subjected to DSA CT angiography to rule out AVM/aneurysm and magnetic resonance imaging (MRI) to rule out tumour bleed. CT scan was repeated after six hours and on third day of admission in case of clinical deterioration.

The criteria for surgical management in supratentorial SICH were patients less than 60 years of age, progressive neurological deficit, GCS of more than five, clot more than $40 \mathrm{cc}$ in volume, mass effect on CT scan and deterioration of neurological status while on conservative treatment. The medical management criteria were patients more than 60 years of age, GCS of five or less, clot less than $40 \mathrm{cc}$ in size, brain stem extension and associated medical disorders.

The criteria for surgical management in infratentorial SICH were patients with clot size of more than three centimeter in diameter, associated hydrocephalus, obliteration of brainstem cisterns and deterioration of neurological status. The medical management criteria were patients with clot size of less than three centimeter in diameter and GCS of less than five.

Open craniotomy was used for evacuating the blood clot for treatment by surgical mode, while those conservatively managed were treated by decongestants. The patients were followed up for one month and after three months of discharge. The outcome was assessed based on Glasgow outcome scale at discharge, one month and three months after discharge.

"Classified Specialist (Surgery and Neurosurgery), Command Hospital (SC) Pune-411040.

Received : 16.03.2006; Accepted : 17.10.2006 


\section{Results}

The study consisted of 60 consecutive patients of SICH in the age group of $10-75$ years. Majority $(51.66 \%)$ were in $5^{\text {th }}$ and $6^{\text {th }}$ decade of life (Table 1 ) and $50 \%$ were males. Majority $(68.33 \%)$ presented within 24 hours of onset and $56 \%$ had GCS $\geq 9$ at presentation. The first symptom was loss of consciousness in 28 (46.66\%), sudden severe headache in 21 (35\%), drowsiness in eight $(13.33 \%)$ and hemiperesis in 46 $(76.66 \%)$ patients. The associated disease at admission were high blood pressure in 36 patients with history of hypertension in 25 . Out of these, 19 patients had history of irregular medication, while seven patients had diabetes mellitus. Three patients had coagulopathy (one each of antiplatelet drug therapy, idiopathic thrombocytopenic purpura and chronic lymphatic leukaemia). One patient had Wagener's granulomatosis. No cause was found in 20/60 (33.33\%) cases.

Majority (45\%) of the clots were lobar followed by basal ganglion bleed (35\%) and intra ventricular haemorraghe (IVH)

Table 1

Age distribution

$\begin{array}{lc}\text { Age in years } & \text { Number of patients }(\mathrm{n}=60) \\ 10-20 & 2 \\ 21-30 & 3 \\ 31-40 & 9 \\ 41-50 & 11 \\ 51-60 & 21 \\ 61-70 & 10 \\ 71-80 & 4\end{array}$

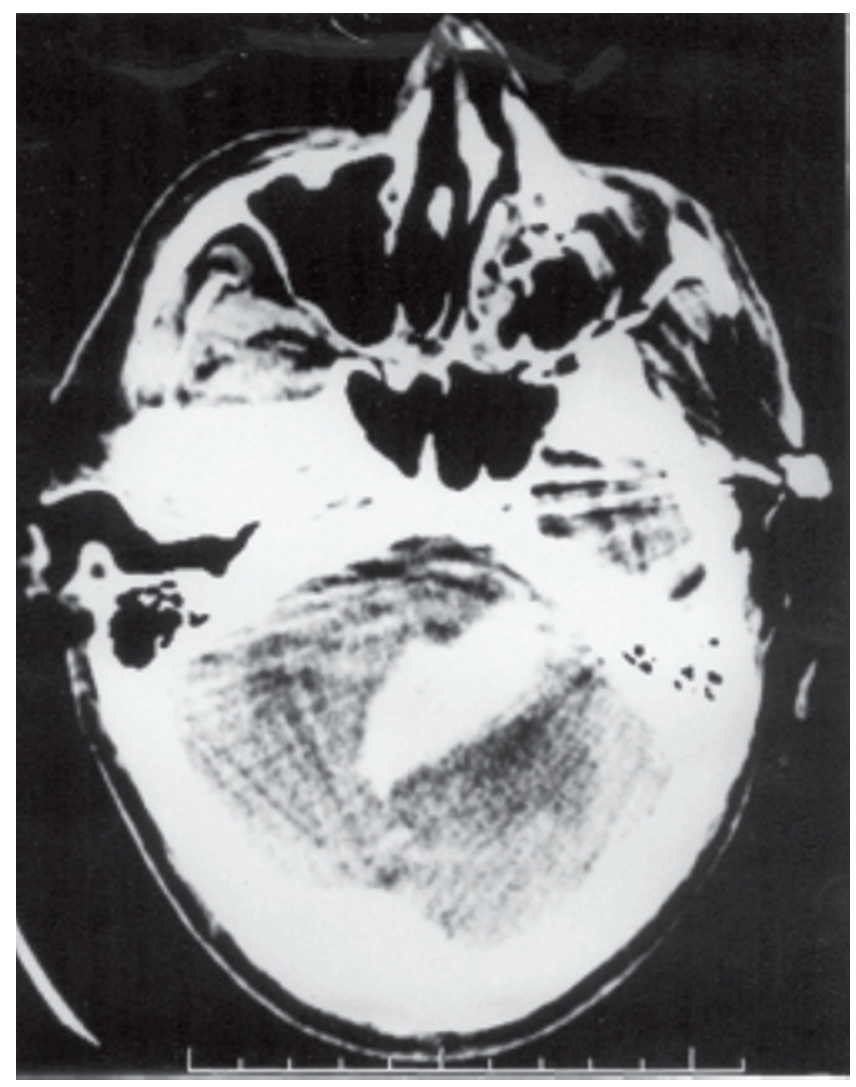

Fig. 1: Infratentorial clot (cerebellar) was seen in $22(36.66 \%)$ cases. Three had brain stem extension and five patients had bleed in the cerebellum. Volume of the clot varied between 5-112.23cc in supratentorial region and 13-22cc in cerebellum. Six patients had associated hydrocephalus and one patient had subsequent infarct in the penumbral area. Majority of the patients with large bleed had mid line shift (58.33\%) and one patient had acute subdural haematoma. Six patients had associated hydrocephalus (Figs.1,2).

Twenty seven cases were operated and rest treated conservatively. A total of 23 cases of supratentorial bleed were operated. Twelve patients had bleed of more than $40 \mathrm{cc}$ and $11(40.74 \%)$ had clots of less than $40 \mathrm{cc}$, of which four had to be operated as GCS deteriorated while on conservative management. One case had recurrent bleed and another had associated spontaneous acute SDH. One of the patients improved from M-1 state while on conservative treatment, two patients had bleed in temporal lobe and three had significant midline shift. Four out of five cases of infratentorial bleed were operated as bleed was more than three centimeter in diameter.

Remaining 33 patients were managed conservatively with anti oedema and antihypertensive medication. Five patients despite having clots more than $40 \mathrm{cc}$ were not operated as two were fully preserved, one did not improve from M-1 status and others had coagulopathy and died before correction.

Generally patients with clots less than $40 \mathrm{cc}$ were well preserved at presentation. The general guidelines for surgery could not be adhered to as two patients with large bleeds did not deteriorate while four with minor clots deteriorated neurologically and were operated. Two patients had small bleed in temporal lobe which had to be operated considering the critical location. Three patients had associated coagulopathy of which two died before correction while one died after surgery. One patient had acute subdural haematoma necessitating evacuation though the clot was small. One patient had repeat bleeding into the operated area and investigation did not reveal any cause.

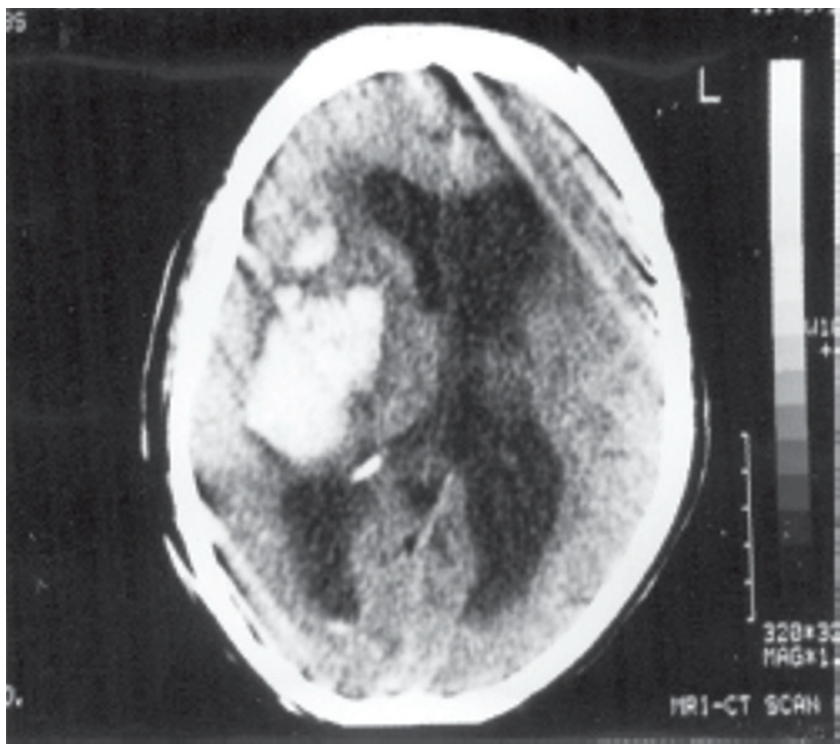

Fig. 2: Large basal ganglia clot (managed conservatively) 
Table 2a

Comparison of GCS at presentation vs GCS at discharge and outcome in conservatively managed group

\begin{tabular}{|c|c|c|c|c|c|c|c|c|c|}
\hline \multirow{2}{*}{$\begin{array}{l}\text { GCS } \\
\text { at admission }\end{array}$} & \multicolumn{4}{|c|}{ Discharge GCS } & \multicolumn{5}{|c|}{ Outcome } \\
\hline & $15-13$ & $12-9$ & $8-5$ & $<5$ & Good & Independent & Dependent & Vegetative & Dead \\
\hline $15-13$ & 10 & 9 & 1 & & 9 & & & & 1 \\
\hline $12-9$ & 11 & 3 & 8 & & 4 & 1 & 5 & & 1 \\
\hline $8-5$ & 9 & 2 & 3 & 4 & & 2 & 2 & & 5 \\
\hline$<5$ & 2 & & & 2 & & & & 1 & 1 \\
\hline
\end{tabular}

$\mathrm{p}=0.0009$, statistically not significant. GCS of one patient was not known as he was managed conservatively and referred after one week.

Table 2b

Comparison of pre operative GCS vs post operative GCS and glasgow outcome scale of surgically managed group

\begin{tabular}{lccccccccc} 
Pre surgical GCS & \multicolumn{3}{c}{ Post surgical GCS } & \multicolumn{5}{c}{ Outcome } \\
& $13-15$ & $12-9$ & $8-5$ & $<5$ & Good & Independent & Dependent & Vegetative & Dead \\
Supratentorial & 2 & 1 & & 1 & & & 1 & \\
$13-15$ & 9 & 3 & 4 & 2 & & 2 & 1 & \\
$12-9$ & 8 & 2 & 2 & 2 & 2 & 1 & 2 & 1 \\
$8-5$ & 4 & & 1 & 3 & 1 & 1 & 2 &
\end{tabular}

$\mathrm{p}=0.51125$, no statistically significant correlations were found. The relation between presurgical GCS and outcome was equivocal.

\section{Infratentorial}

$\begin{array}{llll}13-15 & 2 & 1 & 1 \\ 8-5 & 2 & & \\ <5 & & & 2\end{array}$

$<5$

$\mathrm{p}=0.13534$. In general, the GCS improved after surgery. Statistically no significant difference was found.

Table 3

Clot size vs outcome

\begin{tabular}{|c|c|c|c|c|c|c|}
\hline \multirow{2}{*}{$\begin{array}{l}\text { Clot size } \\
\text { (in } \mathrm{mm} \text { ) }\end{array}$} & \multirow[t]{2}{*}{ Number of cases } & \multicolumn{5}{|c|}{ Outcome } \\
\hline & & Good & Independent & Dependent & Vegetative & Dead \\
\hline$<10$ & 4 & 3 & 1 & & & \\
\hline $11-20$ & 7 & 2 & & 4 & & 1 \\
\hline $21-30$ & 5 & 3 & & 2 & & \\
\hline $31-40$ & 8 & 2 & 2 & 2 & 1 & 2 \\
\hline$>41$ & 8 & 1 & 1 & 1 & & 5 \\
\hline
\end{tabular}

Patients with cerebellar bleeds fared well after evacuation before deterioration. One patient showed growth of intra cerebral haemorraghe (ICH) after three days from $5 \mathrm{cc}$ to $25 \mathrm{cc}$, while another showed infarction after initial bleed emphasizing the prevalence of ischaemia in the penumbra.

The study showed that presenting GCS and clot size had varying outcome (Table $2 \mathrm{a}, 2 \mathrm{~b}, 3$ ). Out of 20 patients with clot size larger than $40 \mathrm{cc}$, eight $(40 \%)$ died, one $(5 \%)$ was in vegetative state and six (30\%) were dependant, but patients with larger bleeds had very poor GCS at admission. Of 39 patients with clot size less than 40cc, 10 (25.64\%) died, two $(5.12 \%)$ patients were in vegetative state and $17(41.02 \%)$ were dependant. Out of 34 patients with GCS of more than 9, nine $(36 \%)$ patients died, seven $(20.58 \%)$ were dependent and eight (52.94\%) were either independent or good. In contrast $(25 / 60)$ patients who presented with GCS of less than 8 , nine $(36 \%)$ died, two $(8 \%)$ were in vegetative state, six $(24 \%)$ were dependent and eight $(32 \%)$ independent or had good outcome. Out of 36 patients with midline shift (shift of $\geq$
$5 \mathrm{~mm}), 18(56 \%)$ died and two $(5.55 \%)$ were in vegetative state, but the difference was not statistically significant. Out of six patients with hydrocephalus, three died and three survived and the difference was statistically insignificant.

The overall mortality in the surgical group was 10 / $27(40.74 \%)$. Out of 23 patients in the supratentorial group nine $(39.13 \%)$ died, while in infratentorial bleeds $20 \%$ died. The overall mortality in patients on conservative treatment was $9 / 33(27.27 \%)$.

\section{Discussion}

Is surgery for $\mathrm{SICH}$ beneficial as compared to conservative treatment? Beginning with Mc Kissock's trial in 1961, seven randomised studies and three meta analysis have confirmed that small clots are better managed conservatively while large clots have no difference in mortality whether treated conservatively or surgically. The treatment of moderate bleed is inconclusive [18]. Tan et al [16], concluded that the 
decision regarding treatment, based on size of haematoma and conscious level may not be sufficient and the answer may lie in physiological studies based on the imaging of penumbra using diffusion perfusion MRI to quantify potential recovery. Shaw et al [19], recommended intra cranial pressure (ICP) monitoring for deciding surgical/ conservative management of these cases. We found that smaller bleeds are better managed conservatively, while optimal management of moderate and large bleeds is inconclusive and there was no difference in the outcome at the end of three months. Generally patients with significant midline shift, acute hydrocephalus and deteriorating neurological status will require surgical evacuation [12-15], however the guidelines are clear for cerebellar haematoma [20-23].

In the study group none of the parameters observed were statistically significant to predict the outcome but the outcome was generally better in patients who were in good neurological status at admission. It was observed that surgically treated group had higher mortality than those treated conservatively. Our study group was small with no control group. We conclude that a larger study with ICP monitoring and better understanding of penumbral ischemia may be required.

The clearest result of the STICH trial has been the uniformly poor outcome in patients presenting with intracerebral haemorrhage with coma[18]. Similar observation was made in our study group. However in patients with deep seated bleeds or neurological deterioration while on conservative treatment, evacuation of haematoma by steriotactic guided method is a better option as compared to open craniotomy $[18,24]$.

\section{Conflicts of Interest}

None identified

\section{References}

1. Berge E, Barer D. Could stroke trails be missing important treatment effects. Cerebrovas Dis 2002; 13:73-5.

2. Broderick JP, Adams HP, Barsan W, et al. Guidelines for management of spontaneous intracerebral hemorrhage. Stroke 1999;30:905-15.

3. Siddique SM, Mandalow AD. Surgical treatment of intracerebral hemorrhage. British Medical Bulletin 2000; 56; 446-56.

4. Mandalow D, Stiner T, Heidelberg. Management of cerebral hemorrhage. $5^{\text {th }}$ Karolinska Stroke update consensus statement. $15^{\text {th }}$ Nov 2004.

5. Quereshi AI, Mohammad YM, et al. A prospective multicentric study to evaluate the feasibility and safety of aggressive antihypertensive treatment in patients with acute intra cerebral hemorrhage. J Intensive Care Med 2005; 20: 34-42.

6. David S, Beskind L. Intracranial hemorrhage update. University of California at Los Angeles. June 29: 2004.
7. Greenberg SM. Cerebral Amyoid angiopathy. Prospects for clinical diagnosis and treatment. Neurology 1988; 51: 690-97.

8. Flemming KD, Wijdicks EF, St Lous EK. Predicting deterioration in patients with lobar hemorrhages. J Neurol Neusurg Psychiatry 1999;66:600-5.

9. Dennis M. Outcome after brain haemorrhage. Cerebrovas Dis 2003; 16: 9-13.

10. Zhu XL, Chan MS, Poon WS. Spontaneous intracranial hemorrhage, which patient needs diagnostic cerebral angiography. A prospective study of 206 cases and review of literature. Stroke 1997;25:1406-9.

11. Donnan GA, Davis SM. Surgery for intracerebral hemorrhage: An evidence poor zone. Stroke 2003; 34: 1569-70.

12. Fernandes HF, Gregson BG, Siddique MS, Mandelow AD. Surgery in Intracerebral Hemorrhage: the uncertainity continues. Personal communications. Stroke 2000; 81: 2511-6.

13. Morgenstern LB, Frankowski RF, Shedden P, Pasteur, et al. Surgical treatment for intracerebral hemorrhage. A single centre randomised clinical trial. Neurology 1998; 51: 1359-63.

14. Zuccarello M, Brott T, Dextex L, et al. Early surgical treatment for supratentorial intracerebral hemorrhage. A randomised feasibility study. Stroke 1999; 30: 1833-7.

15. Hanky GJ, Hon C. Surgery for primary intracerebral hemorrhage, is it safe and effective. A systemic review of case series and randomised trials. Stroke 1997; 28: 2126-32.

16. Tan SH, Ng PY, Yeo TT, Wong SH. Hypertensive Basal Ganglion Hemorrhage: A prospective study comparing surgical and nonsurgical mangement. Surg Neurol 2001; 56: 287-93.

17. Kothari R, Britt T, Broderick J, Barsan W, et al. The ABCs of measuring intracerebral hemorhage volume. Stroke 1996; 27 : 1304-13.

18. Gregson BA, Fernandes HM, Murray GD, et al. Early Surgery versus initial conservative treatment in patients with spontaneous supratentorial intracerebral haemotomas in International Surgical Trial in Intracerebral Haemorrhage (STICH): a randomised trial. Lancet 2005; 365: 387-97.

19. Shaw MDM, Mandelow AD, Teasdate GM, Murray GD, et al. Alterations to STICH protocol. Lancet 2003; 362: 1244-9.

20. Kobayashi S, Sato A, Kageyama Y, Nakamura H, Watanabe Y, et al.. Treatment of hypertensive cerebellar hemorrhage, Surgical or conservative management? Comment in Neurosurgery 1995; 34: 246-51.

21. Mathew P, Teasdate G, Baman A, Oluoch-Olnya D. Neurological management of cerebellar hemotoma and infarct. Jr of Neurology Neurosurgery and Psychiatry 1995; 59: 287 92.

22. d'avella D, Servadei F, Scerrati M, Tomei G, et al. Traumatic intracerebellar hemorrhage. Clinico radiological analysis of 81 patients. Neurosurgery 2002;50:16-25.

23. Takahira N, Hiroki O. Surgery verses conservative treatment for intracerebral hemorrhage - is there an end to the long controversy. Lancet 2005; 365: 361-2.

24. Nakano T, Ohkuma H, Ebina K, Suzuki S. Neuroendoscopic surgery for intracerebral hemorrhage: comparison with traditional therapies. Minim Invas Neurosurgery 2003; 46: 27883. 